\title{
Inhibition of the secretion of LH in ovariectomised pigs by sustained but not repeated acute elevation of cortisol in the absence but not the presence of oestradiol
}

\author{
A I Turner ${ }^{1}$, P H Hemsworth ${ }^{\mathbf{2}}$, B J Canny ${ }^{1}$ and A J Tilbrook ${ }^{1}$ \\ ${ }^{1}$ Department of Physiology, Monash University, Clayton, 3168, Victoria, Australia \\ ${ }^{2}$ Animal Welfare Centre, Victorian Institute of Animal Science, Sneydes Rd, Werribee, 3030, Victoria, Australia \\ (Requests for offprints should be addressed to A J Tilbrook; Email: alan.tilbrook@med.monash.edu.au)
}

\begin{abstract}
Prolonged stress is known to impair reproduction. It has been proposed that reproduction will also be impaired when a severe acute stress occurs during a period of elevated plasma concentrations of oestradiol, such as during the follicular phase of the oestrous cycle. In this experiment, we hypothesised that repeated acute and sustained elevation of cortisol would suppress the secretion of LH in ovariectomised pigs and that these effects would be enhanced in the presence of oestradiol negative feedback. Cortisol (or vehicle) was administered 12 hourly to ovariectomised pigs ( $n=6 /$ treatment) for 8 days in the absence of oestradiol treatment and for a further 8 days during treatment with oestradiol. Vehicle was administered to 'control' pigs, 10 or $20 \mathrm{mg}$ cortisol was administered i.v. to pigs to produce 'repeated acute' elevation of cortisol and $250 \mathrm{mg}$ cortisol was administered i.m. to pigs to give a 'sustained' elevation of cortisol. Both before and during treatment with oestradiol, plasma concentrations of $\mathrm{LH}$ were monitored on the day before treatment, on the 4th
\end{abstract}

and 8th days of treatment and following an i.v. injection of $\mathrm{GnRH}$ at the end of the 8th day of treatment. The repeated acute elevation of cortisol did not impair any parameters of LH secretion (i.e. mean plasma concentrations of $\mathrm{LH}$, pulse amplitude or frequency, pre-LH pulse nadir or the $\mathrm{LH}$ response to $\mathrm{GnRH}$ ) in the absence or in the presence of oestradiol. In contrast, when the elevation of cortisol was sustained, the mean plasma concentrations of LH and the pre-LH pulse nadir were significantly $(P<0.05)$ lower on the 8th day of treatment than on the day before treatment and on the 4th day of treatment. Nevertheless, no other parameters of LH secretion were affected and these effects only occurred in the absence (not in the presence) of oestradiol. In conclusion, cortisol needed to be elevated for more than 4 days to impair the secretion of $\mathrm{LH}$, and oestradiol did not enhance the impact of cortisol on $\mathrm{LH}$ secretion in ovariectomised pigs.

Journal of Endocrinology (1999) 163, 477-486

\section{Introduction}

Although it has been proposed that acute stress at a critical stage of the oestrous cycle, such as prior to oestrus and ovulation, can disrupt reproductive performance (Moberg 1985), experiments that we have conducted in pigs have provided no support for this (Turner et al. 1998a,b). For instance, when substantial activation of the hypothalamo-pituitary-adrenal axis occurred due to the imposition of a negative handling procedure every $24 \mathrm{~h}$ for 4-13 days prior to oestrus, there was no impairment of reproduction (Turner et al. 1998b). To impair reproduction in female pigs, stress may need to be more severe and/or more frequent than that imposed in our previous experiments. Many studies have demonstrated that administering cortisol in a manner which resulted in its sustained elevation in plasma impaired various aspects of reproduction in female pigs (Liptrap 1970, Scholten \& Liptrap
1978, Barb et al. 1982, Fonda et al. 1984, Estienne et al. 1991) suggesting that cortisol is important in mediating the stress-induced impairment of reproduction. For instance, twice daily i.m. injection of cortisol, which resulted in a sustained elevation of plasma concentrations of cortisol, blocked the luteinizing hormone (LH) surge and ovulation in gilts (Barb et al. 1982). Since the secretion of LH is central to reproduction, the measurement of plasma concentrations of $\mathrm{LH}$ has often been used to assess the effects of stress (Blake 1975, Doney et al. 1976, Martin et al. 1981, Stoebel \& Moberg 1982, Rasmussen \& Malven 1983, Dobson 1988, Norman et al. 1994, Tilbrook et al. 1999) and of administering hormones of the hypothalamopituitary-adrenal axis (Barb et al. 1982, Hennessy \& Williamson 1983, Paterson et al. 1983, Fonda et al. 1984, Pearce et al. 1988, Frautschy et al. 1989, Estienne et al. 1991) on reproduction in females. For instance, prolonged treatment of ovariectomised pigs with cortisol inhibited 
the secretion of LH (Estienne et al. 1991). In contrast, there have been no studies in which cortisol has been administered in a manner which resulted in the acute elevation of plasma concentrations of cortisol, as would occur in an acute stress response, and it is not known if repeated acute treatment with cortisol will also inhibit the secretion of LH. Such treatment would allow manipulation of the magnitude and frequency of elevations of plasma concentrations of cortisol to determine if substantial elevations which occur more frequently than once per day are required to impair reproduction.

While the impact of the hypothalamo-pituitary-adrenal axis on the reproductive axis has long been recognised (Moberg 1985), there is also evidence that gonadal steroids influence the activity of the hypothalamo-pituitaryadrenal axis (Handa et al. 1994, Da Silva 1995). For instance, plasma concentrations of cortisol were greatest when plasma concentrations of oestradiol were elevated in rats (Critchlow et al. 1963, Kitay 1963) and in rhesus macaques (Smith \& Norman 1987). Consequently, it might be expected that the impact of stress on reproduction would also be greatest when circulating concentrations of oestradiol are highest. Indeed, in rhesus macaques the secretion of $\mathrm{LH}$ was impaired when a stressor was imposed during the follicular phase of the menstrual cycle but not when the same stressor was imposed during the luteal phase of the menstrual cycle (Norman et al. 1994). While oestrogen may enhance the activity of the hypothalamo-pituitary-adrenal axis and the impact of stress on reproduction, it is not known if this sex steroid influences the actions of cortisol to inhibit the secretion of LH or, conversely, if cortisol influences the feedback actions of oestradiol on LH. These issues were investigated in this experiment using ovariectomised pigs given repeated acute treatment with cortisol in the presence or absence of oestradiol negative feedback. Thus, this experiment tested the hypotheses that the repeated acute and sustained elevation of cortisol will disrupt spontaneous and gonadotrophin-releasing hormone $(\mathrm{GnRH})$-induced secretion of LH in ovariectomised pigs and that these effects will be enhanced in ovariectomised pigs treated with oestradiol.

\section{Materials and Methods}

\section{Animals}

Twenty-four pigs (17 sows and 7 gilts; Large White $\times$ Landrace) were ovariectomised 6-12 months before the experiment. The age of pigs at the commencement of the experiment was 517-700 days for sows and 396-533 days for gilts. Venous catheters were inserted in all pigs (Takken \& Williams 1981) 5 or 6 days before the experiment and the pigs were housed in groups of 3 with a space allowance of $2.4 \mathrm{~m}^{2}$ per pig. The care and experimental use of animals conformed with the requirements of the
Australian Prevention of Cruelty to Animals Act 1986 and the NHMRC Australian code of practice for the care and use of animals for scientific purposes.

\section{Procedure}

A schematic representation of the treatments and protocol used in this experiment is given in Fig. 1. The pigs were allocated randomly to 4 treatments (6 pigs/treatment). Treatment consisted of i.v. injections $(2 \mathrm{ml})$ and i.m. injections $(2 \mathrm{ml})$ of cortisol or the appropriate vehicle for cortisol at $0900 \mathrm{~h}$ and $1900 \mathrm{~h}$ for 8 days. The vehicle for i.v. administration of cortisol was saline and that for i.m. administration of cortisol was corn oil. Thus, pigs in the 'control' treatment received i.v. injections of saline via their indwelling catheter and i.m. injections of corn oil. There were two treatments which involved repeated acute elevation of cortisol. Pigs in the ' $10 \mathrm{mg}$ repeated acute' and '20 mg repeated acute' treatment groups received i.v. injections of either $10 \mathrm{mg}$ or $20 \mathrm{mg}$ cortisol (hydrocortisone sodium succinate, Solu-Cortef Sterile Powder, Upjohn Pty Ltd, Rydalmere, NSW, Australia) in saline, and i.m. injections of corn oil. The decision to use these doses was based on a study where an i.v. injection of $5 \mathrm{mg}$ cortisol in pubertal gilts elevated plasma concentrations of cortisol in a similar manner to that which followed an acute stressor (Dalin et al. 1993). Pigs in the 'sustained' elevation of cortisol treatment group received i.v. injections of saline and i.m. injections of $250 \mathrm{mg}$ cortisol (hydrocortisone 21-acetate, Sigma, St Louis, MO, USA) in corn oil. This treatment has previously been shown to result in a sustained elevation of cortisol and a disruption of the LH surge and ovulation in gilts (Barb et al. 1982). The plasma concentrations of cortisol which resulted from these treatments were assessed on the second day of treatment. Samples of blood $(10 \mathrm{ml})$ were collected 50, 40, 30, 20, 10 and $0 \mathrm{~min}$ before and 2, 5, 10, 15, 20, 30, 40, 50, 60, 70, 80, 90, 100, 110 and $120 \mathrm{~min}$ after the $0900 \mathrm{~h}$ treatment injections. Concentrations of cortisol were measured in plasma harvested from these samples.

To determine plasma concentrations of LH, blood samples were collected every $10 \mathrm{~min}$ from $0900 \mathrm{~h}$ to $1700 \mathrm{~h}$ on the day before treatment commenced (day - 1) and on the 4th day of treatment (day 4), and from $0800 \mathrm{~h}$ to $1600 \mathrm{~h}$ on the 8 th day of treatment (day 8). At $1600 \mathrm{~h}$ on the 8th day of treatment, an i.v. injection of $20 \mu \mathrm{g}$ GnRH (luteinizing hormone releasing hormone, Auspep, Parkville, Victoria, Australia) was administered to all pigs and blood samples were collected 5, 10, 15, 20, 30, 40, 50, $60,70,80,90,100,110$ and $120 \mathrm{~min}$ thereafter. Concentrations of LH were assessed in plasma from these samples. In addition, plasma concentrations of cortisol were measured in blood samples collected 3, 4, 5, 6, 7, 8 and $9 \mathrm{~h}$ after the morning treatment on days $-1,4$ and 8 of treatment. 
Treatments:

controls

$10 \mathrm{mg}$ repeated acute

$20 \mathrm{mg}$ repeated acute

sustained i.v. vehicle and i.m. vehicle

i.v. $10 \mathrm{mg}$ cortisol and i.m. vehicle

i.v. $20 \mathrm{mg}$ cortisol and i.m. vehicle

i.v. vehicle and i.m. $250 \mathrm{mg}$ cortisol

$$
\begin{aligned}
& n=6 \\
& n=6 \\
& n=6 \\
& n=6
\end{aligned}
$$

indicates days of twice daily treatment

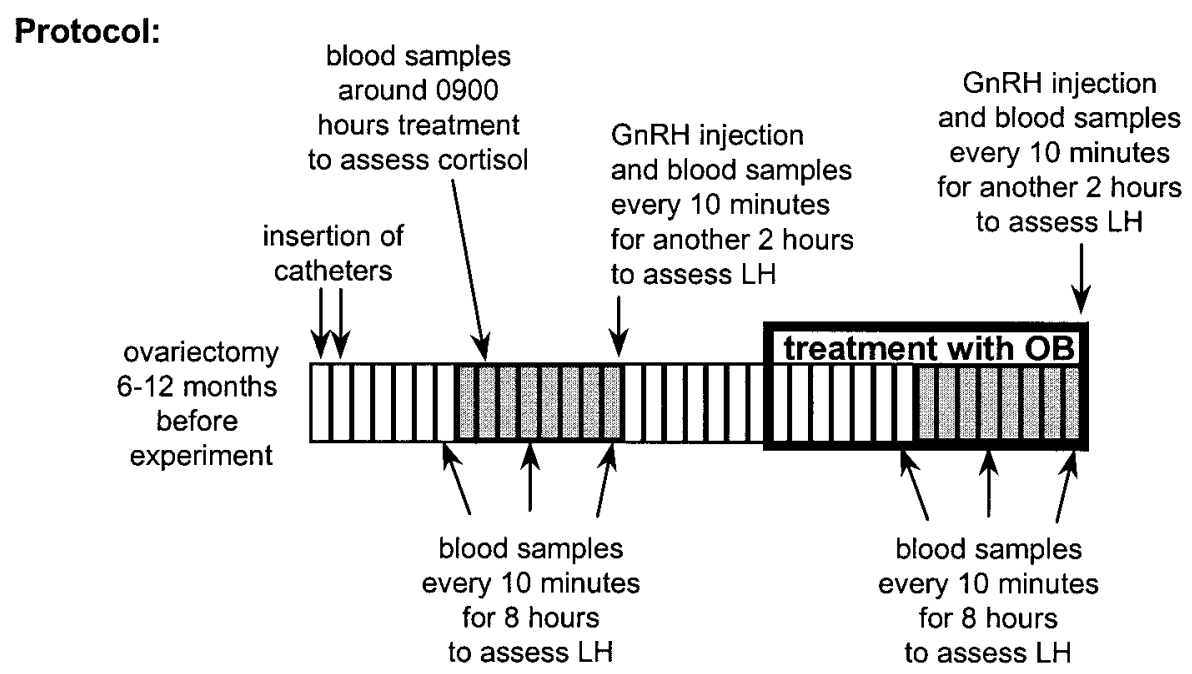

Figure 1 The treatment regimen and a schematic representation of the protocol. $\mathrm{OB}=$ oestradiol. Further explanation is given in the text.

The effects of sustained and repeated acute elevation of cortisol on the secretion of $\mathrm{LH}$ were also assessed when the pigs were undergoing treatment with oestradiol (Fig. 1). Injections (i.m.) of oestradiol (75 $\mathrm{g} ; \beta$-oestradiol 3benzoate, Sigma) were administered twice daily $(0700 \mathrm{~h}$ and $1900 \mathrm{~h}$ ) commencing one week after the end of the first treatment period. These injections were continued for the remainder of the experiment. After one week of injections of oestradiol, samples of blood were again collected at 10-min intervals from $0900 \mathrm{~h}$ to $1700 \mathrm{~h}$ (day -1 ). On the following day, the treatment regimen used in the first part of the experiment was resumed for 8 days. As in the first period of treatment, samples of blood were collected over $8 \mathrm{~h}$ on the 4 th and 8 th days of treatment and for a further $2 \mathrm{~h}$ following injection of GnRH on the 8th day. Plasma concentrations of $\mathrm{LH}$ and cortisol were measured in plasma harvested from these blood samples.

\section{Radioimmunoassays}

Cortisol radioimmunoassay Total plasma concentrations of cortisol were measured, following extraction of plasma using dichloromethane, by a radioimmunoassay which was developed for use in fetal sheep plasma (Bocking et al. 1986) and which has since been validated for use in pig plasma (Turner et al. 1998a). The mean ( \pm s.E.M.) recovery of $\left[{ }^{3} \mathrm{H}\right]$ cortisol from plasma after the extraction procedure was $92 \pm 2 \%$. There were 19 assays conducted with a mean ( \pm s.E.M.) assay sensitivity of $0 \cdot 6 \pm 0 \cdot 1 \mathrm{ng} / \mathrm{ml}$. Samples that fell below the assay sensitivity were assayed again using a larger volume of sample. The intra-assay coefficients of variation were $6.3 \%$ at $33.0 \mathrm{ng} / \mathrm{ml}, 5 \cdot 6 \%$ at $28.8 \mathrm{ng} / \mathrm{ml}$ and $7 \cdot 6 \%$ at $53 \cdot 1 \mathrm{ng} / \mathrm{ml}$. The interassay coefficients of variation were $8 \cdot 2 \%$ at $33.7 \mathrm{ng} / \mathrm{ml}, \quad 16 \cdot 1 \%$ at $29 \cdot 3 \mathrm{ng} / \mathrm{ml}$ and $13.3 \%$ at $53 \cdot 8 \mathrm{ng} / \mathrm{ml}$.

LH radioimmunoassay Plasma concentrations of $\mathrm{LH}$ were determined using a double-antibody radioimmunoassay which was developed for analysis of porcine LH (pLH) by Niswender et al. (1970), modified by Peacock (1991) and Klupiec (1995) and further modified for use in our laboratory. Primary anti-body (\#566 antiporcine LH serum, Dr GD Niswender, Colorado State 
University, Fort Collins, CO, USA) was raised in rabbits (Niswender et al. 1970) and pLH (LER-1786-3, Dr L E Reichert Jr, The Albany Medical College, Albany, NY, USA), for use in standards and tracer, was purified according to the procedure described by Reichert (1964). Second antibody (goat anti-rabbit serum, Dr I R Young, Monash University, Clayton, Victoria, Australia) was raised in goats against rabbit immunoglobulin G. Purified $\mathrm{pLH}$ was labelled with radioactive iodine $\left({ }^{125}\right.$ I, NEN Life Science Products, Boston, MA, USA) using the Iodogen (1,3,4,6-tetrachloro-3 $\alpha, 6 \alpha$-di-phenylglycouril, Sigma) protocol described by Salacinski et al. (1981). Sixteen assays were conducted with a mean ( \pm s.E.M.) assay sensitivity of $0 \cdot 17 \pm 0.02 \mathrm{ng} / \mathrm{ml}$. Samples that fell below the assay sensitivity were assayed again using a larger volume of sample. The intra-assay coefficients of variation were $7 \cdot 3 \%$ at $0.4 \mathrm{ng} / \mathrm{ml}$ and $8.8 \%$ at $0.6 \mathrm{ng} / \mathrm{ml}$. The interassay coefficients of variation were $16 \cdot 4 \%$ at $0.5 \mathrm{ng} / \mathrm{ml}$ and $18 \cdot 1 \%$ at $0 \cdot 8 \mathrm{ng} / \mathrm{ml}$.

\section{Identification of LH pulses}

A modification of the procedure described by Karsch et al. (1987) was used to define pulses of LH. Pulses were defined as abrupt increases in the concentration of $\mathrm{LH}$ that were greater than the assay sensitivity, exceeded the preceding value by at least three times the mean standard deviation of the LH concentrations determined by the relevant assay, and were followed by a progressive decline at a rate consistent with the half-life of LH in pigs of $28.0 \mathrm{~min}$ (Esbenshade et al. 1986). The mean plasma concentration of LH was calculated as the mean of all points in the sampling period. The amplitude of $\mathrm{LH}$ pulses was calculated as the difference between the peak and the preceding nadir. The number of pulses per hour was calculated as the total number of pulses in a sampling period divided by the number of hours in the sampling period (i.e. $8 \mathrm{~h}$ ). The baseline was calculated as a mean of the pre-LH pulse nadir values. If there were no $\mathrm{LH}$ pulses identified in a sampling period, the mean plasma concentration of LH was used as the baseline value and the pulse amplitude and number of pulses per hour were recorded as 0 .

\section{Statistical analyses}

Plasma concentrations of cortisol around the $0900 \mathrm{~h}$ injections on the 2nd day of treatment were compared between treatments using repeated measures analysis of variance. Post hoc multiple comparisons for this and subsequent analyses of variance were made using least significant differences. Comparisons were made between subjects for all analyses of variance, except where otherwise stated. Repeated measures analysis of variance was also used to compare between treatments for the plasma concentrations of cortisol from 3 to $9 \mathrm{~h}$ after treatment injections on each day of blood sampling. The variances of these raw data were not homogeneous so the data were subjected to $\log 10$ transformation prior to analysis. Mean plasma concentrations of LH, pulse amplitude, the number of pulses per hour and pre-LH pulse nadir were also analysed by repeated measures analysis of variance but post hoc multiple comparisons were made within subjects for these parameters. The LH response to GnRH was compared between treatments using repeated measures analysis of variance, and two-way analysis of variance was used to analyse the area under the LH response to GnRH curve and the peak of this curve.

\section{Results}

\section{Plasma concentrations of cortisol}

Around $0900 \mathrm{~h}$ treatment on the $2 \mathrm{nd}$ day of treatment Plasma concentrations of cortisol in pigs in the $10 \mathrm{mg}$ repeated acute and the $20 \mathrm{mg}$ repeated acute elevation of cortisol treatment groups were significantly $(P<0 \cdot 05)$ higher than those in control pigs two minutes after treatment (Fig. 2). These concentrations remained significantly $(P<0.05)$ greater than those in the control pigs until $20 \mathrm{~min}$ after treatment in pigs in the $10 \mathrm{mg}$ repeated acute elevation of cortisol treatment group, and until $110 \mathrm{~min}$ after treatment in pigs in the $20 \mathrm{mg}$ repeated acute elevation of cortisol treatment group $(P=0.076$ 100 min after treatment). Plasma concentrations of cortisol in pigs in the sustained elevation of cortisol treatment group were significantly $(\mathrm{P} \leq 0.05)$ higher than those in control pigs $50 \mathrm{~min}$ after treatment and for the remainder of the sampling period (120 min; Fig. 2, inset).

From 3 to $9 \mathrm{~h}$ after treatment on each day of sampling Throughout the course of the experiment, plasma concentrations of cortisol from 3 to $9 \mathrm{~h}$ after treatment were significantly $(P<0.05)$ higher in pigs in the sustained elevation of cortisol treatment group than in pigs in all other treatment groups (Fig. 3). Furthermore, plasma concentrations of cortisol were significantly $(P<0 \cdot 05)$ greater in pigs in the $20 \mathrm{mg}$ repeated acute elevation of cortisol treatment group than in control pigs. These treatment effects were not related to the day of treatment or the presence/absence of oestradiol.

\section{Plasma concentrations of $\mathrm{LH}$}

Mean concentrations Plasma concentrations of $\mathrm{LH}$ were significantly $(P<0 \cdot 05)$ higher in the absence of oestradiol than during treatment with oestradiol (Fig. 4; top panel). There was no significant change in the mean plasma concentration of LH from day -1 to days 4 or 8 of treatment in pigs in the control, $10 \mathrm{mg}$ repeated acute or $20 \mathrm{mg}$ repeated acute elevation of cortisol treatment 


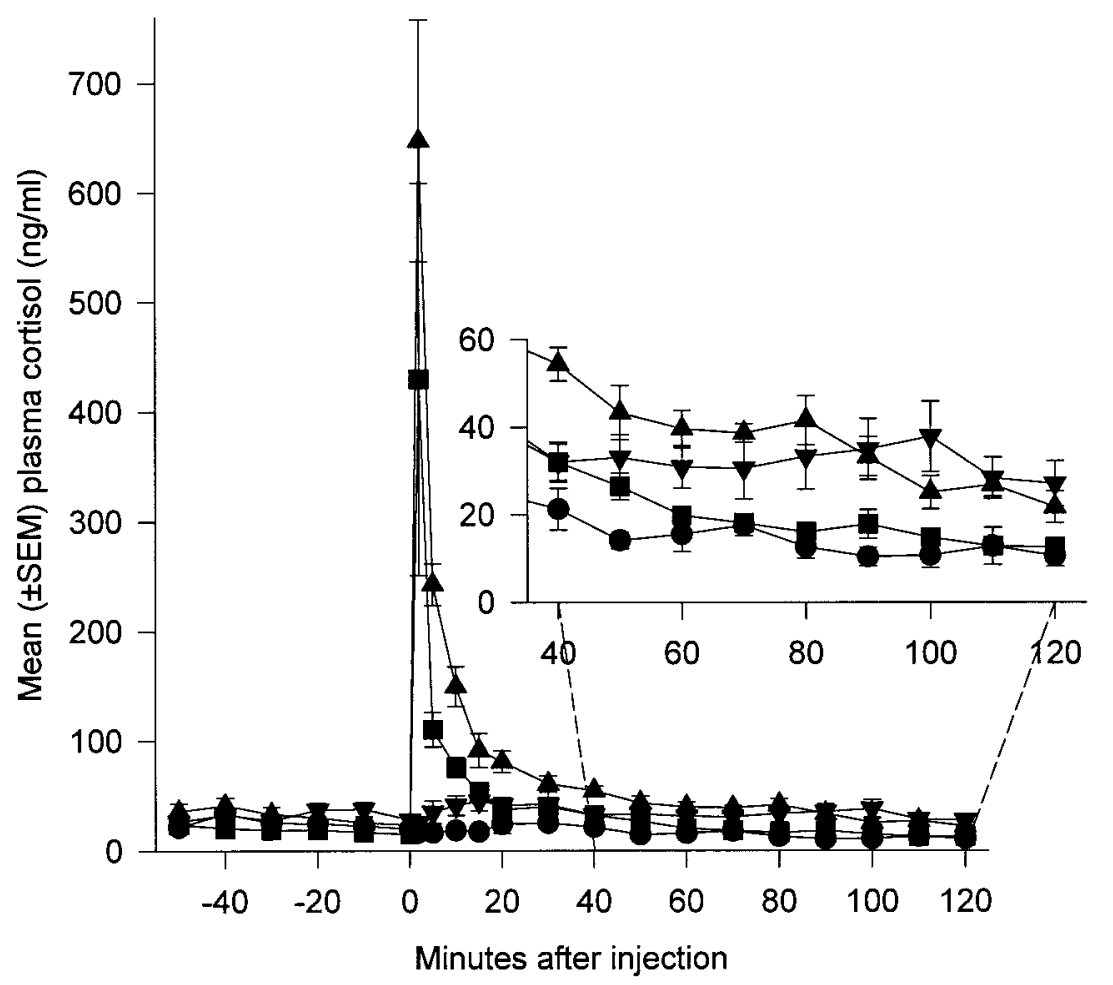

Figure 2 Mean ( \pm S.E.M.) plasma concentrations of cortisol $(\mathrm{ng} / \mathrm{ml})$ for pigs in the control $(\boldsymbol{\bullet}), 10 \mathrm{mg}$ repeated acute $(\boldsymbol{\square}), 20 \mathrm{mg}$ repeated acute $(\boldsymbol{\Delta})$ and sustained $(\boldsymbol{\nabla})$ elevation of cortisol treatment groups from 50 min before to $120 \mathrm{~min}$ after treatment (and from 40 to $120 \mathrm{~min}$ after treatment with an expanded scale; inset). This treatment occurred at $0900 \mathrm{~h}$ on the 2 nd day of treatment. Significant differences are described in the Results section.

groups in the presence or absence of oestradiol or in pigs in the sustained elevation of cortisol treatment group in the presence of oestradiol. In contrast, in the absence of oestradiol, pigs in the sustained elevation of cortisol treatment group had significantly $(P<0 \cdot 05)$ lower mean plasma concentrations of $\mathrm{LH}$ on the 8th day of treatment than before treatment and on the 4th day of treatment.

Amplitude of LH pulses Overall, the amplitude of $\mathrm{LH}$ pulses was significantly $(P<0 \cdot 05)$ greater in the absence of oestradiol than during treatment with oestradiol (Fig. 4; second panel from top). Nevertheless, the amplitude of LH pulses on the 4th and 8th days of treatment was not significantly different to that recorded before treatment in pigs in any treatment group either before or during treatment with oestradiol.

Frequency of $\mathrm{LH}$ pulses Pulses of $\mathrm{LH}$ were significantly $(P<0 \cdot 05)$ more frequent (as measured by the number of LH pulses per hour) in the absence of oestradiol than during treatment with oestradiol (Fig. 4; third panel from top). The number of LH pulses per hour did not change from before treatment to the 4th or 8 th day of treatment in pigs in any treatment group either before or during treatment with oestradiol.

Pre-LH pulse nadir Across all treatments, the baseline concentrations of LH (as measured by the pre-LH pulse nadir) were significantly $(P<0 \cdot 05)$ higher in the absence of oestradiol than during treatment with oestradiol (Fig. 4; bottom panel). There were no significant changes in the baseline concentrations of $\mathrm{LH}$ from before treatment to the 4th or 8th day of treatment in pigs in the control or $10 \mathrm{mg}$ repeated acute elevation of cortisol treatment groups in the absence or presence of oestradiol or in pigs in the $20 \mathrm{mg}$ repeated acute or sustained elevation of cortisol treatment groups in the presence of oestradiol. In the absence of treatment with oestradiol, pigs in the $20 \mathrm{mg}$ repeated acute elevation of cortisol treatment group had significantly $(P<0 \cdot 05)$ higher mean pre-LH pulse nadir on the 8 th day of treatment than on the day prior to treatment and on the 4th day of treatment. In contrast, pigs in the sustained elevation of cortisol treatment group had a significantly $(P<0 \cdot 05)$ lower mean pre-LH pulse nadir on the 8 th day of treatment than on the day before treatment and on the 4th day of treatment. 

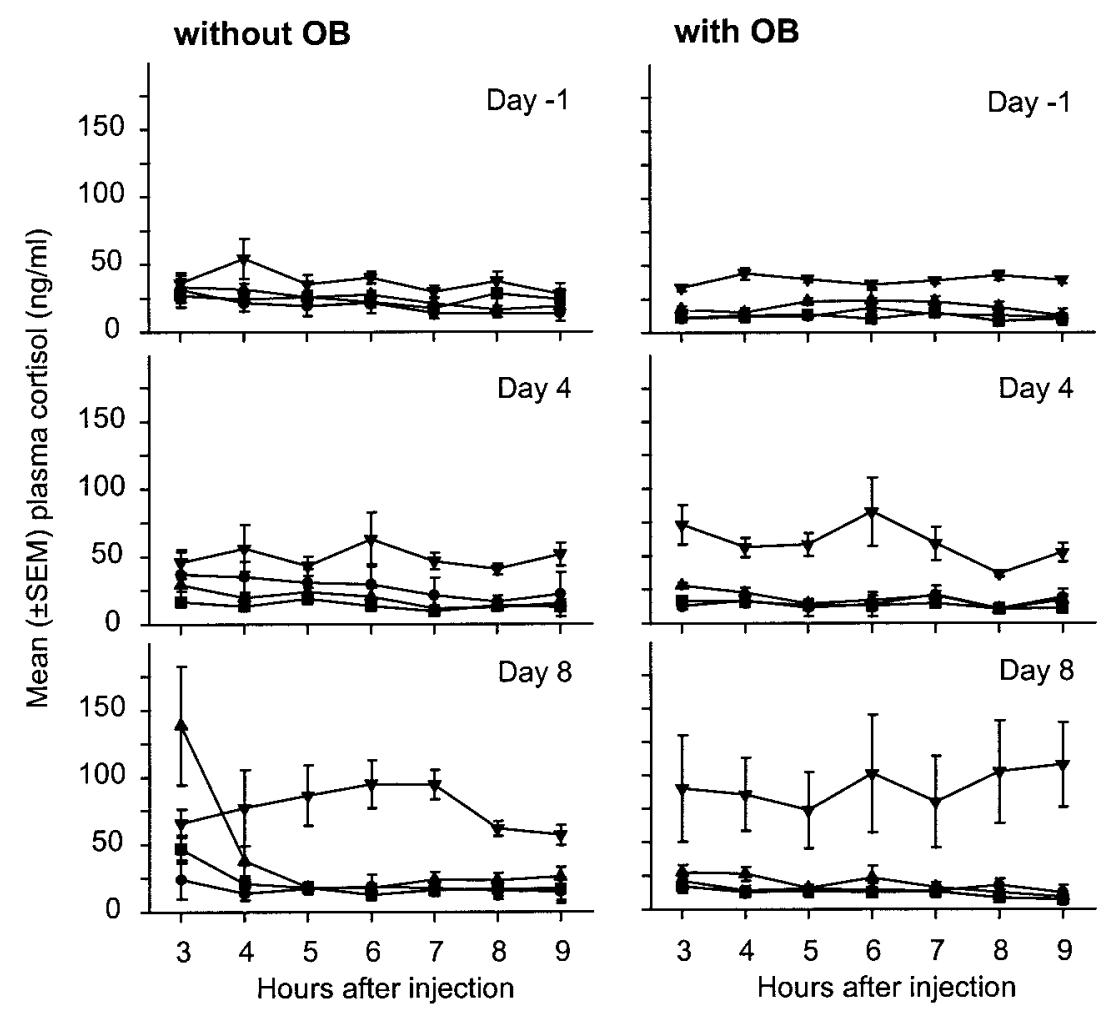

Figure 3 Mean ( \pm S.E.M.) plasma concentrations of cortisol $(\mathrm{ng} / \mathrm{ml})$ from 3 to $9 \mathrm{~h}$ after treatment in pigs in the control $(\bullet), 10 \mathrm{mg}$ repeated acute $(\mathbf{\square}), 20 \mathrm{mg}$ repeated acute $(\boldsymbol{\Delta})$ and sustained $(\boldsymbol{\nabla})$ elevation of cortisol treatment groups on the day prior to treatment (day -1 ) and on the 4th (day 4) and 8th (day 8) day of treatment both before treatment with oestradiol (without $\mathrm{OB}$ ) and during treatment with oestradiol (with OB). Significant differences are described in the Results section.

\section{LH response to GnRH}

While there was a significant $(P<0 \cdot 05)$ elevation of plasma concentrations of LH in pigs in all treatments following i.v. injection of $20 \mathrm{mg} \mathrm{GnRH}$ both before and during treatment with oestradiol (Fig. 5), the LH response to GnRH was significantly $(P<0.05)$ greater in the absence of oestradiol than when oestradiol was present. Repeated measures analysis of variance found no significant differences between treatments in the plasma concentrations of $\mathrm{LH}$ following injection of $\mathrm{GnRH}$ either in the presence or absence of oestradiol. Furthermore, the area under the LH response to $\mathrm{GnRH}$ curve $(\mathrm{ng} / \mathrm{ml} / 120 \mathrm{~min})$ and the peak height of this response $(\mathrm{ng} / \mathrm{ml})$ were significantly $(P<0 \cdot 05)$ greater in the absence of oestradiol $(120 \pm 16,2 \cdot 3 \pm 0 \cdot 3$ respectively) than in the presence of oestradiol ( $54 \pm 4$, $1 \cdot 2 \pm 0 \cdot 1$ respectively) but there were no significant differences between treatments for these parameters.

\section{Discussion}

In this experiment, the repeated acute elevation of cortisol did not impair the secretion of $\mathrm{LH}$ in ovariectomised pigs in the absence or in the presence of oestradiol negative feedback, indicating that this aspect of reproduction is insensitive to such treatment. Moreover, the GnRHinduced release of LH was not affected by the repeated acute elevation of cortisol in ovariectomised pigs, suggesting that this treatment did not impair the ability of the pituitary gland to respond to $\mathrm{GnRH}$, and this result was not influenced by treatment with oestradiol. These results are consistent with those of previous experiments in our laboratory (Turner et al. 1998a,b), which showed that the imposition of acute stressors that resulted in the repeated acute elevation of plasma concentrations of cortisol did not impair reproduction. Also in keeping with previous studies (Barb et al. 1982, Fonda et al. 1984, Estienne et al. 1991) is the finding that the sustained elevation of cortisol reduced plasma concentrations of LH. Nevertheless, this did not occur until the 8th day of treatment, and did not occur in ovariectomised pigs treated with oestradiol. This result suggests that, in animals where the secretion of $\mathrm{LH}$ is not restrained by negative feedback of ovarian hormones, plasma concentrations of cortisol need to be elevated for a considerable period before plasma concentrations of LH are reduced. It would appear that, even 


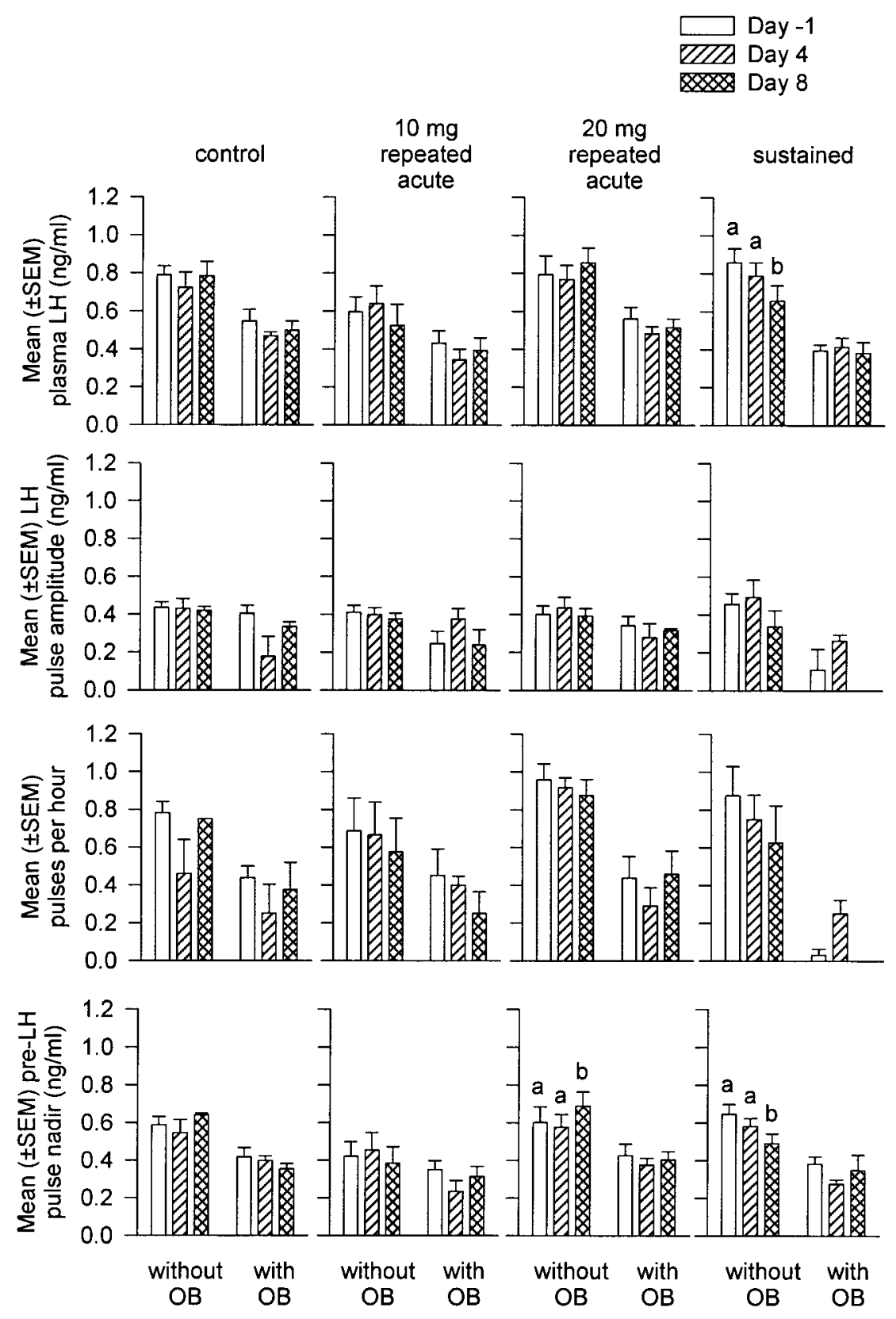

Figure 4 Mean ( \pm S.E.M.) plasma concentrations of $\mathrm{LH}(\mathrm{ng} / \mathrm{ml}$; top panel), $\mathrm{LH}$ pulse amplitude ( $\mathrm{ng} / \mathrm{ml}$; second panel from top), pulses per hour (third panel from top) and pre-LH pulse nadir $(\mathrm{ng} / \mathrm{ml}$; bottom panel) for pigs in the control, $10 \mathrm{mg}$ repeated acute, $20 \mathrm{mg}$ repeated acute and sustained elevation of cortisol treatment groups on the day prior to treatment (day -1$)$ and on the 4th (day 4) and 8th (day 8) day of treatment both before administration of oestradiol (without OB) and during administration of oestradiol (with OB). The absence of a bar represents a value of 0 . Different superscripts on bars within a panel indicate a significant $(P<0 \cdot 05)$ difference.

though cortisol is capable of reducing plasma concentrations of LH when its elevation in the plasma is sustained, the repeated acute elevation of cortisol in this experiment was not sufficient to achieve this.
The sustained elevation of cortisol achieved in this experiment may have been ineffective in reducing plasma concentrations of LH in ovariectomised pigs treated with oestradiol because the LH parameters were reduced by the 


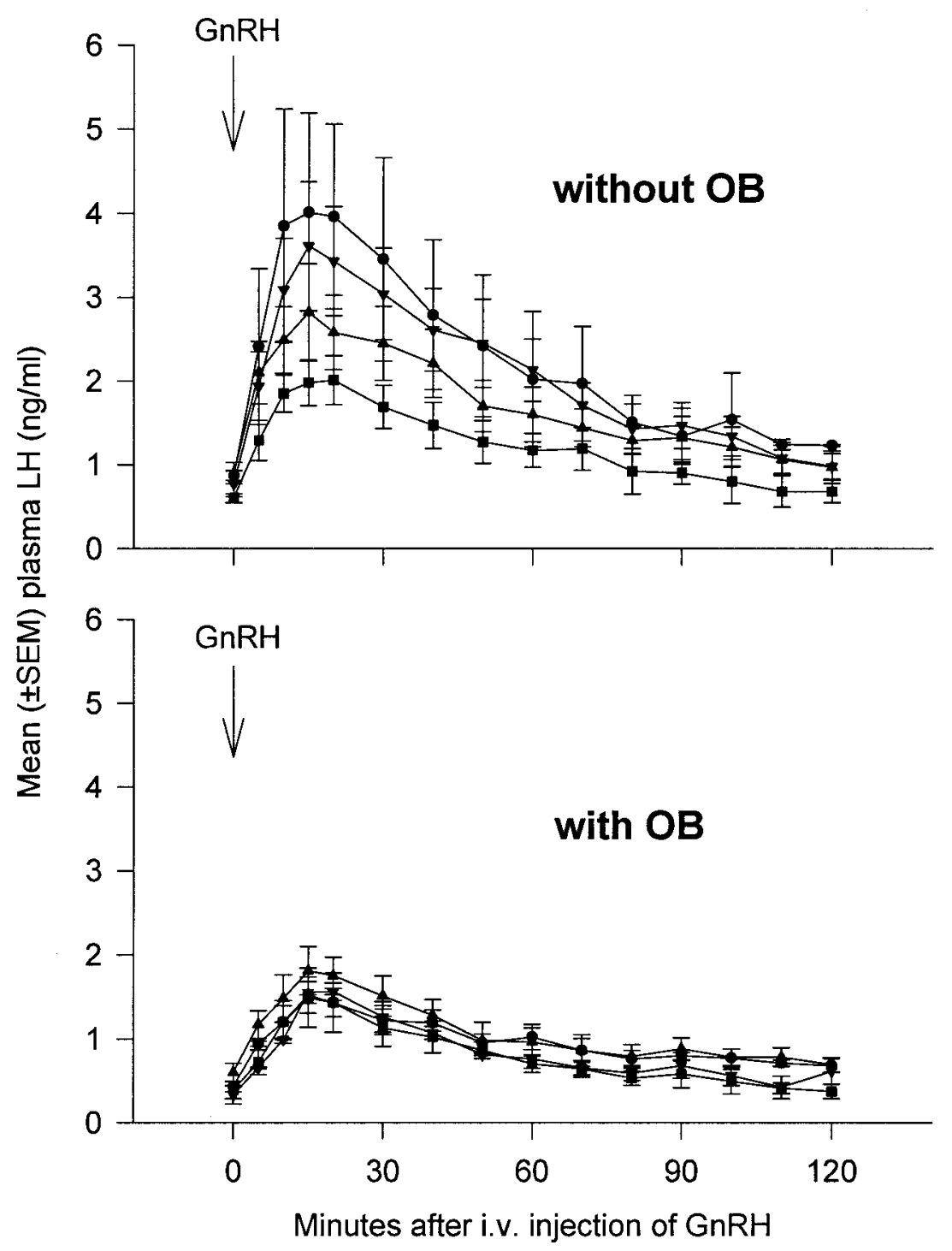

Figure 5 Mean ( \pm S.E.M.) plasma concentrations of $\mathrm{LH}(\mathrm{ng} / \mathrm{ml})$ following an i.v. injection of $20 \mathrm{mg} \mathrm{GnRH}$ in pigs in the control $(\mathbf{)}), 10 \mathrm{mg}$ repeated acute (ם), $20 \mathrm{mg}$ repeated acute $(\boldsymbol{\Delta})$ and sustained $(\boldsymbol{\nabla})$ elevation of cortisol treatment groups on the 8th day of treatment, both before administration of oestradiol (without OB; upper panel) and during administration of oestradiol (with OB; lower panel). There were no significant differences between treatments.

negative feedback actions of oestradiol to an extent where differences between treatments were masked. Alternatively, the detrimental actions of cortisol on the secretion of LH may have been directly attenuated by oestradiol. This latter explanation does not support the finding that in rhesus macaques, $6 \mathrm{~h}$ of chair restraint inhibited the secretion of LH during the follicular phase of the menstrual cycle, when oestrogens are elevated, but not during the luteal phase (Norman et al. 1994), or the finding, in ovariectomised sheep, that $4 \mathrm{~h}$ of isolation/restraint stress inhibited the secretion of $\mathrm{LH}$ in the presence and absence of oestradiol (Tilbrook et al. 1999). Nevertheless, there might be species differences in the ability of oestrogens to influence the impact of stress on reproduction and/or the discrepancies between the results of these studies might be due to differences in the experimental paradigms. For instance, while stressors were imposed in the studies on rhesus macaques (Norman et al. 1994) and sheep (Tilbrook et al. 1999), cortisol was injected in the current experiment. 
The mechanism by which the sustained elevation of cortisol reduced the mean plasma concentrations of LH in the absence of oestradiol is not clear. This reduction in mean LH was not associated with a decrease in the frequency or amplitude of $\mathrm{LH}$ pulses. This is surprising as it would be expected that cortisol would act at the hypothalamus (Estienne et al. 1991) and/or at the pituitary (Pearce et al. 1988) to disrupt the secretion of LH and that this would be manifest in an impairment of the frequency and/or amplitude of LH pulses. Instead, the reduction in mean plasma concentrations of LH was associated with a reduction in mean pre-LH pulse nadir suggesting that basal secretion of LH was impaired. The site at which cortisol acted to produce this result is not clear and could include the hypothalamus and/or pituitary. The finding that the responsiveness of the pituitary to exogenous GnRH was not altered by treatment with cortisol supports studies by Fonda et al. (1984) and by Estienne et al. (1991) but not that by Pearce et al. (1988) which found that, in pre-pubertal pigs, the LH response to GnRH was lower when GnRH was administered mid-way through a 1-h infusion of cortisol than during an equivalent infusion of saline. Nevertheless, our results indicate that the response of the pituitary to GnRH was not affected by cortisol. The approach used in the current experiment assessed the ability of the pituitary to release stores of LH from gonadotrophs in response to a large dose of exogenous GnRH and not the ability of the pituitary to respond to the continuous endogenous pulses of GnRH that occur in ovariectomised animals. The decrease in the pre- $\mathrm{LH}$ pulse nadir may, therefore, be due to a decrease in the ability of the pituitary to respond to endogenous pulses of $\mathrm{GnRH}$ and/or a decrease in the GnRH stimulus from the hypothalamus, and/or direct effects at the gonadotroph to alter the intracellular mechanisms which regulate synthesis and secretion of LH. Since the secretion of LH was not inhibited by the administration of cortisol during treatment with oestradiol, there is no evidence in this experiment to suggest that cortisol increased the negative feedback actions of oestrogens.

Although repeated acute elevation of cortisol did not impair LH secretion, an increase in the pre-LH pulse nadir occurred on the 8th day of twice daily i.v. treatment with $20 \mathrm{mg}$ cortisol, in the absence of oestradiol. This apparent increase in basal secretion of $\mathrm{LH}$ did not occur in pigs in the $10 \mathrm{mg}$ repeated acute elevation of cortisol treatment group, nor in either of the repeated acute elevation of cortisol treatment groups in the presence of oestradiol. Furthermore, despite the increase in basal plasma concentrations of $\mathrm{LH}$ in these pigs, there were no changes in the mean plasma concentrations of LH or the frequency or amplitude of LH pulses. The mechanism and the physiological significance of this increase in basal plasma concentrations of LH are unknown.

In conclusion, the results of this experiment indicate that the repeated acute elevation of cortisol, similar to that which would follow severe acute stress, did not inhibit the secretion of LH in ovariectomised pigs, in the absence or in the presence of oestradiol negative feedback. These results provide further support for the contention that reproduction in female pigs appears to be resistant to repeated acute stress. Indeed, it appears that, in ovariectomised pigs, the elevation of plasma concentrations of cortisol needs to be sustained for more than 4 days to achieve suppression of LH. Furthermore, this effect may be influenced by oestradiol because, in this experiment, 8 days of sustained elevation of plasma concentrations of cortisol reduced plasma concentrations of $\mathrm{LH}$ in ovariectomised pigs in the absence but not in the presence of oestradiol. The decrease in plasma concentrations of $\mathrm{LH}$ was associated with a decrease in basal concentrations of $\mathrm{LH}$ but there were no changes in the frequency or amplitude of $\mathrm{LH}$ pulses or the $\mathrm{LH}$ response to an injection of $\mathrm{GnRH}$.

\section{Acknowledgements}

We thank Paul Hughes, Jim Tilton, Lisa Newman, Bruce Schirmer, Kim Heasman, Nicole Carter, Ashleigh Michael, Tina Chamberlain and Kate Breuer for technical assistance. We also thank Gareth Evans for helping us establish our pLH assay, David Caddy for advice on statistical analyses, Paul Hughes for his constructive comments on this manuscript and John Barnett for technical advice. This research was funded by the Pig Research and Development Corporation of Australia.

\section{References}

Barb CR, Kraeling RR, Rampacek GB, Fonda ES \& Kiser TE 1982 Inhibition of ovulation and LH secretion in the gilt after treatment with ACTH or hydrocortisone. Journal of Reproduction and Fertility 64 85-92.

Blake CA 1975 Effects of 'stress' on pulsatile luteinizing hormone release in ovariectomized rats. Proceedings of the Society for Experimental Biology and Medicine 148 813-815.

Bocking AD, McMillen IC, Harding R \& Thorburn GD 1986 Effect of reduced uterine blood flow on fetal and maternal cortisol. Journal of Developmental Physiology 8 237-245.

Critchlow V, Liebelt RA, Bar-Sela M, Mountcastle W \& Lipscomb HS 1963 Sex difference in resting pituitary-adrenal function in the rat. American Journal of Physiology 205 807-815.

Dalin AM, Magnusson U, Haggendal J \& Nyberg L 1993 The effect of thiopentone-sodium anesthesia and surgery, relocation, grouping, and hydrocortisone treatment on the blood levels of cortisol, corticosteroid-binding globulin, and catecholamines in pigs. Journal of Animal Science 71 1902-1909.

Da Silva JA 1995 Sex hormones, glucocorticoids and autoimmunity: facts and hypotheses. Annals of the Rheumatic Diseases 54 6-16.

Dobson H 1988 Effect of stress during shearing on the $\mathrm{LH}$ response to $\mathrm{GnRH}$ in anoestrous ewes. Journal of Agricultural Science 110 673-676.

Doney JM, Gunn RG, Smith WF \& Carr WR 1976 Effects of pre-mating environmental stress, ACTH, cortisone acetate or metyrapone on oestrus and ovulation in sheep. Journal of Agricultural Science 87 127-132. 
Esbenshade KL, Vogel MJ \& Traywick GB 1986 Clearance rate of luteinizing hormone and follicle-stimulating hormone from peripheral circulation in the pig. Journal of Animal Science 62 1649-1653.

Estienne MJ, Barb CR, Kesner JS, Kraeling RR \& Rampacek GB 1991 Luteinizing hormone secretion in hypophysial stalk-transected gilts given hydrocortisone acetate and pulsatile gonadotropinreleasing hormone. Domestic Animal Endocrinology 8 407-414.

Fonda ES, Rampacek GB \& Kraeling RR 1984 The effect of adrenocorticotropin or hydrocortisone on serum luteinizing hormone concentrations after adrenalectomy and/or ovariectomy in the prepuberal gilt. Endocrinology 114 268-273.

Frautschy SA, Gaon D \& Liptrap RM 1989 Effect of dexamethasone on gonadotrophin secretion in the gonadectomized sow and boar. Canadian Journal of Veterinary Research 53 490-492.

Handa RJ, Burgess LH, Kerr JE \& O'Keefe JA 1994 Gonadal steroid hormone receptors and sex differences in the hypothalamopituitary-adrenal axis. Hormones and Behavior 28 464-476.

Hennessy DP \& Williamson P 1983 The effects of stress and of ACTH administration in hormone profiles, oestrus and ovulation in pigs. Theriogenology 20 13-26.

Karsch FJ, Cummins JT, Thomas GB \& Clarke IJ 1987 Steroid feedback inhibition of pulsatile secretion of gonadotropin-releasing hormone in the ewe. Biology of Reproduction 36 1207-1218.

Kitay JI 1963 Pituitary adrenal function in the rat after gonadectomy and gonadal hormone replacement. Endocrinology 73 253-260.

Klupiec C 1995 Endocrinological and nutritional aspects of seasonal infertility of domestic pigs. PhD Thesis. University of Sydney.

Liptrap RM 1970 Effect of corticotrophin and corticosteroids on oestrus, ovulation and oestrogen excretion in the sow. Journal of Endocrinology 47 197-205.

Martin GB, Oldham CM \& Lindsay DR 1981 Effect of stress due to laparoscopy on plasma cortisol levels, the preovulatory surge of LH, and ovulation in the ewe. Theriogenology 16 39-44.

Moberg GP 1985 Influence of stress on reproduction: measure of well-being. In Animal Stress, pp 245-267. Ed GP Moberg. Baltimore: Williams \& Wilkins.

Niswender GD, Reichert LE Jr \& Zimmerman DR 1970 Radioimmunoassay of serum levels of luteinizing hormone throughout the estrous cycle in pigs. Endocrinology 70 576-580.

Norman RL, McGlone J \& Smith CJ 1994 Restraint inhibits luteinizing hormone secretion in the follicular phase of the menstrual cycle in rhesus macaques. Biology of Reproduction 50 16-26.

Paterson AM, Cantley TC, Esbenshade KL \& Day BN 1983 Glucocorticoids and estrus in swine. II. Plasma concentrations of estradiol-17 beta, glucocorticoids and luteinizing hormone in ovariectomized gilts given estradiol benzoate and triamcinolone acetonide. Journal of Animal Science 56 466-470.

Peacock A 1991 Environmental and social factors affecting seasonal infertility in pigs. PhD Thesis. University of Sydney.

Pearce GP, Paterson AM \& Hughes PE 1988 Effect of short-term elevations in plasma cortisol concentration on LH secretion in prepubertal gilts. Journal of Reproduction and Fertility 83 413-418.

Rasmussen DD \& Malven PV 1983 Effects of confinement stress on episodic secretion of LH in ovariectomized sheep. Neuroendocrinology 36 392-396.

Reichert LE Jr 1964 Preparation of purified porcine luteinizing hormone. Endocrinology 75 970-972.

Salacinski PR, McLean C, Sykes JE, Clement-Jones VV \& Lowry PJ 1981 Iodination of proteins, glycoproteins, and peptides using a solid-phase oxidizing agent, 1,3,4,6-tetrachloro-3 alpha,6 alphadiphenyl glycoluril (iodogen). Analytical Biochemistry 117 136-146.

Scholten JA \& Liptrap RM 1978 A role for the adrenal cortex in the onset of cystic ovarian follicles in the sow. Canadian Journal of Comparative Medicine 42 525-533.

Smith CJ \& Norman RL 1987 Influence of the gonads on cortisol secretion in female rhesus macaques. Endocrinology 121 2192-2198.

Stoebel DP \& Moberg GP 1982 Repeated acute stress during the follicular phase and luteinizing hormone surge of dairy heifers. Journal of Dairy Science 65 92-96.

Takken A \& Williams KC 1981 A simplified procedure for long-term catheterisation of the anterior vena cava in adult pigs. Australian Veterinary Journal 57 17-20.

Tilbrook AJ, Canny BJ, Serapiglia MD, Ambrose TJ \& Clarke IJ 1999 Suppression of the secretion of luteinizing hormone due to isolation/restraint stress in gonadectomised rams and ewes is influenced by sex steroids. Journal of Endocrinology 160 469-481.

Turner AI, Hemsworth PH, Hughes PE, Canny BJ \& Tilbrook AJ $1998 a$ The effect of repeated boar exposure on cortisol secretion and reproduction in gilts. Animal Reproduction Science 51 143-154.

Turner AI, Hemsworth PH, Hughes PE \& Tilbrook AJ $1998 b$ Repeated acute activation of the hypothalamo-pituitary-adrenal axis prior to and during estrus did not affect reproductive performance in gilts. Biology of Reproduction 58 1458-1462.

\section{Received 5 January 1999}

Revised manuscript received 25 May 1999

Accepted 4 August 1999 